\title{
Pegada hídrica cinza no cultivo de tomate no semiárido brasileiro
}

\section{Gray water footprint in cultivation of tomato in Brazilian semi-arid}

\author{
Hallyson Oliveira $\mathbb{D}^{1}$; André Alisson Rodrigues da Silva ${ }^{\mathbb{D}}{ }^{1}$; Robson Fábio Alves de Souza $\mathbb{D}^{1}$; Patrícia \\ da Silva Costa $\mathbb{D}^{1}$; Francisco Wesley Alves Pinheiro ${ }^{1}{ }^{1}$; Thiago Galvão Sobrinho $\mathbb{D}^{2}$
}

${ }^{1}$ Doutorandos em Irrigação e Drenagem, Universidade Federal de Campina Grande. Campina Grande, Paraíba. Fones: (83) 9 9155-0616, (83) 9 8689-8061, (83) 9 98873-9495, (83) 9 9659-6615, (83) 9 9622-2831, e-mails: hallysonoliveira_@hotmail.com, andrealisson_cgpb@hotmail.com, rfabiosouza@yahoo.com.br, patriciaagroambiental@gmail.com, wesley.ce@hotmail.com; ${ }^{2}$ Mestrando em Irrigação e Drenagem, Universidade Federal de Campina Grande. Campina Grande, Paraíba. Fone: (83) 9 9869-9323, e-mail: tgs_galvao@ hotmail.com.

\begin{tabular}{l} 
A R T I G O \\
\hline Recebido: 08/12/2018 \\
Aprovado: $10 / 03 / 2019$
\end{tabular}

Palavras-chave: Solanum lycopersicum Agroquímicos Agricultura

Key words:

Solanum lycopersicum

Agrochemicals

Agriculture

\begin{abstract}
R E S U M O
A pegada hídrica cinza (PHC) é definida como o volume de água doce necessário para diluir poluentes incorporados nas camadas superficiais e subsuperficiais do solo, por meio da emissão de agrotóxicos na produção agrícola. Diante disso, o objetivo com esta pesquisa foi avaliar a pegada hídrica cinza no cultivo de tomate em regiões do semiárido brasileiro. $\mathrm{O}$ trabalho foi desenvolvido nos municípios de Parelhas e Equador, ambos localizados no estado do Rio Grande do Norte. Foi realizado um levantamento dos principais poluentes, além das condições ambientais de solo e clima, em seguida, foram utilizados modelos matemáticos para estimar a pegada hídrica cinza. Os agrotóxicos avaliados foram: Evidence, LannateBr, Karate 50 EC, Sportak 450 EC, Sencor 480, Ridomil Gold e Confidor S. O inseticida Ridomil Gold (Clorotalonil) foi considerado bastante ofensivo para a produção de tomate neste estudo, a aplicação do mesmo deve ser evitada, sendo necessário sua substituição por outro que requeira menos água doce para sua diluição. Já os agrotóxicos Lannate BR (Metomil), Karate 50 EC (Lambda-Cialotrina) e Sportak 450 EC (Procloraz) foram os que apresentaram menor exigência de água para diluição.
\end{abstract}

\section{A B S T R A C T}

The gray water footprint (GWF) is defined as the volume of fresh water needed to dilute contaminants incorporated into the surface and subsurface layers of the soil, through the emission of agrochemicals in agricultural production. Therefore, the objective of this research was to evaluate the gray water footprint in tomato cultivation in Brazilian semiarid regions. The study was developed in the municipalities of Parelhas and Equador, both located in the state of Rio Grande do Norte. It was carried out a survey of the main pollutants, besides the environmental conditions of soil and climate, soon after the use of mathematical models to estimate the gray water footprint. The pesticides evaluated were Evidence, Lannate Br, Karate 50 EC, Sportak 450 EC, Sencor 480, Ridomil Gold and Confidor S. The insecticide Ridomil Gold (Chlorothalonil) was considered to be very offensive for tomato production in this study, its application should be avoided, and its replacement should be replaced by one that requires less fresh water for dilution. On the other hand, the pesticides Lannate BR (Methomyl), Karate 50 EC (Lambda-Cialotrina) and Sportak 450 EC (Procloraz) were the ones that presented less water requirement for dilution.

\section{INTRODUÇÃO}

A água é um recurso natural de fundamental importância para a vida no planeta Terra, notadamente pelas suas diversas funções nos organismos e sistemas biológicos. Ressalte-se que, devido suas múltiplas funções, a água vem sendo explorada para diversas finalidades, dentre as quais, destaca- se o uso agrícola, sobretudo, por consumir mais de $70 \%$ da água doce captada (LIMA et al., 2018).

Devido ao incremento da utilização de recursos hídricos, foram desenvolvidos métodos para caracterizar, delimitar a distribuição espaço-temporal e monitorar a variação da escassez hídrica no mundo, o que têm contribuído para a compreensão do panorama atual da disponibilidade e demanda de água para atividades específicas, como, por

\section{Revista Verde}

ISSN 1981-8203

Pombal, Paraíba, Brasil v. 14, n.2, abr.-jun, p.197-203, 2019

doi: $10.18378 /$ rvads.v14i2.6189 
exemplo, irrigação e pecuária, em diversas localidades (HOEKSTRA et al., 2012).

Dentre as principais técnicas utilizadas para o mapeamento e monitoramento do panorama hídrico mundial, a pegada hídrica vem ganhando notoriedade, isso porque permite monitorar os efeitos da escassez de água em uma determinada região geográfica, possibilitando seu uso como ferramenta de avaliação, e consequentemente, pode ser usada na gestão dos recursos hídricos (COSTA et al., 2018).

A pegada hídrica total é composta pelas pegadas hídricas verde, azul e cinza. A pegada hídrica cinza é definida como um indicador do grau de poluição da água utilizada em determinado processo de produção, através de determinado poluente. Além disso, esta fração é caracterizada pelo volume de água necessário para assimilar a carga de poluentes, baseado nas concentrações em condições naturais e nos padrões ambientais existentes (SANTIAGO et al., 2017).

É importante destacar que a pegada hídrica cinza, vem sendo utilizada como indicador do consumo de água para diversas culturas e atividades agrícolas (LOVARELLI et al., 2016), como por exemplo na suinocultura (PALHARES, 2014), indústria sucroalcooleira (SANTIAGO et al., 2017), além de estimativa do consumo em instituições de ensino (COSTA et al., 2018), configurando-se uma ferramenta importante no auxílio da tomada de decisões sobre o consumo de água.

Embora existam informações científicas (PAGE et al., 2012; RAMÍREZ et al., 2015) relacionadas à pegada hídrica da cultura do tomate (Lycopersicon esculentum Mill.), pouco se sabe sobre este indicador, sobretudo da pegada hídrica cinza, para o cultivo do tomate nas condições edafoclimáticas dos municípios de Parelhas e Equador, no estado do Rio Grande do Norte.

O controle da poluição causada pelo uso indiscriminado de agroquímicos é de grande relevância para a preservação dos recursos hídricos da região semi-árida do Brasil, proporcionando a sustentabilidade da agricultura e dos recursos hídricos. Devido a importância substancial da preservação dos recursos hídricos e valor econômico das hortaliças, especialmente o tomate, objetivou-se com o presente trabalho avaliar a pegada hidrica cinza para o cultivo de tomate em regiões semiáridas do Nordeste brasileiro.

\section{MATERIAL E MÉTODOS}

O cálculo da pegada hídrica cinza (PHC) se baseia em um estudo sistemático e sequencial, por meio de pesquisas específicas, relacionadas aos fatores que estão intimamente ligados ao favorecimento da lixiviação ou escoamento do produto químico nas camadas superficiais e subterrâneas do solo. Dentre esses fatores, destacam-se o coeficiente de partição do carbono (Koc), a precipitação média da região estudada, o teor de matéria orgânica no solo e as práticas agrícolas na propriedade em questão.

Com base neste estudo, analisou-se a PHC de oito agrotóxicos utilizados em plantios de tomate nos municípios de Parelhas e Equador, localizados no estado do Rio Grande do Norte, de acordo com a pesquisa estabelecida por Silva e Moreira (2012). Sendo assim, foram verificados inicialmente os valores da taxa de aplicação do produto comercial (TACP), a concentração da substância ativa do produto (CP) e o número de aplicações necessárias no ciclo do tomate (NA), os quais foram obtidos nas bulas de cada agroquímico. A taxa de aplicação da substância ativa (TAS) foi calculada através da multiplicação dos valores de TACP, CP e NA.

As frações de lixiviação/escoamento $(\alpha)$ das substâncias químicas nas camadas superficiais e subsuperficiais, foram analisadas de acordo com Tabela proposta por Franke et al. (2013). Os fatores de acarretamento de lixiaviação/escoamento foram divididos em três categorias: propriedades físico-químicas da substância aplicada, condições ambientais e práticas de gestão agrícola. Além disso, para distinguir os potenciais de lixiviação/escoamento para cada fator analisado, foram atribuídos valores de 0 a 1 , em que 0 equivale a um potencial muito baixo, 0,33 baixo, 0,67 igual é considerado elevado e 1 corresponde ao potencial muito alto (Tabela 1).

Tabela 1. Fatores que influenciam o potencial de lixiviação/escoamento $(\alpha)$.

\begin{tabular}{|c|c|c|c|c|c|c|c|}
\hline \multicolumn{8}{|c|}{ Agroquímicos } \\
\hline \multirow[t]{3}{*}{ Categoria } & & \multirow[t]{3}{*}{ Fator } & $\begin{array}{c}\text { Potencial de } \\
\text { Lixiviação e } \\
\text { Vazão }\end{array}$ & $\begin{array}{l}\text { Muito } \\
\text { Baixo }\end{array}$ & Baixo & Alto & Muito Alto \\
\hline & & & Valor $(\mathrm{S})$ & 0,00 & 0,33 & 0,67 & 1,00 \\
\hline & & & Peso $(\mathrm{P})$ & & & & \\
\hline \multirow{3}{*}{\multicolumn{2}{|c|}{$\begin{array}{l}\text { Propriedades } \\
\text { Químicas }\end{array}$}} & $\mathrm{K}_{\mathrm{oc}}\left(\mathrm{L} \mathrm{kg}^{-1}\right)$ & 20 & $>1000$ & $1000-200$ & $200-50$ & $<50$ \\
\hline & & $\mathrm{PL}\left(\mathrm{D}_{\mathrm{T} 50}\right.$ dias $)$ & 15 & $<10$ & $10-30$ & $30-100$ & $>100$ \\
\hline & & $\mathrm{PE}\left(\mathrm{D}_{\mathrm{T} 50}\right.$ dias $)$ & 10 & $<10$ & $10-30$ & $30-100$ & $>100$ \\
\hline \multirow{6}{*}{$\begin{array}{l}\text { Fatores } \\
\text { Ambientais }\end{array}$} & \multirow{4}{*}{ Solo } & TSL & 15 & Argila & Silte & Franco & Areia \\
\hline & & TSE & 10 & Areia & Franco & Silte & Argila \\
\hline & & Teor de MO & & Ótimo & Bom & Médio & Ruim \\
\hline & & $\left(\operatorname{dag} \mathrm{Kg}^{-1}\right)$ & 10 & $>7,00$ & $4,01-7,00$ & $2,01-4,00$ & $<2,00$ \\
\hline & \multirow{2}{*}{ Clima } & $\mathrm{IP}(\mathrm{mm})$ & 5 & Baixa & Moderada & Alta & Muito Alta \\
\hline & & $\mathrm{P}(\mathrm{mm})$ & 5 & $<600$ & $600-1200$ & $1200-1800$ & $>1800$ \\
\hline $\begin{array}{l}\text { Práticas } \\
\text { Culturais }\end{array}$ & & PM & 10 & Ótimo & Bom & Ruim & Muito Ruim \\
\hline
\end{tabular}


Pegada hídrica cinza no cultivo de tomate no semiárido brasileiro

Relacionando os valores encontrados de potencial de lixiviação/escoamento ( $\mathrm{Si}$ ) com o peso de cada fator (Wi), obteve-se o fator adimensional $\alpha$, utilizando a equação (1).

$\alpha=\alpha \min +\left[\frac{\sum \operatorname{sixwi}}{\sum w i}\right] x(\alpha \max -\alpha \min )$

Em que, $\alpha_{\max }-$ fração de lixiviação-vazão máxima; $\alpha_{\min }-$ fração de lixiviação-vazão mínima; $S_{\mathrm{i}}-$ potencial de lixiviação-escoamento; $\mathrm{W}_{\mathrm{i}}$ - peso do fator.

As frações mínimas e máximas lixiviação/escoamento para as substâncias químicas em estudo foram: o mínimo $(\alpha \min =0,0001)$ e o máximo $(\alpha \max =0,1)$, conforme Franke et al. (2013).

Multiplicando os valores de $\alpha$ com TAS, obteve-se a carga poluente (L) aplicada de cada substância nas camadas superficiais e subterrâneas do solo.

As concentrações máximas $\left(\mathrm{C}_{\max }\right)$ permitidas dos poluentes selecionados foram obtidas através de portais, sites e legislações que tratam sobre padrões de qualidade da água em seu estado natural. No caso do Brasil, utilizou-se a Resolução CONAMA no 357/2005 (BRASIL, 2005) para águas doces Classe II. Em casos de não obtenção dos valores de $\mathrm{C}_{\max }$ na legislação brasileira, foram utilizadas legislações da União Européia (EUR, 2008), Conselho Canadense de Ministros do Meio Ambiente (CMME, 2018) e Agência de Proteção do Meio Ambiente dos Estados Unidos (US-EPA, 2018), pois de acordo com Franke et al. (2013), estas normas estão atualizadas e são cientificamente confiáveis. Sendo assim, calculou-se a Pegada Hídrica Cinza $\left(\mathrm{PHC}, \mathrm{m}^{3}\right)$, conforme a equação (2).

$$
\mathrm{PHC}=\frac{L}{\text { Cmax-Cnat }}
$$

Em que, PHC - pegada hídrica cinza $\left(\mathrm{m}^{3}\right)$; L - Carga poluente da substância $(\mathrm{t}) ; \mathrm{C}_{\max }-$ Concentração máxima admissível do poluente no meio aquático receptor $\left(\mathrm{kg} . \mathrm{m}^{-3}\right)$;
Cnat - Concentração natural do poluente considerado no meio aquático receptor $\left(\mathrm{kgm}^{-3}\right)$, sendo este considerado igual a 0 devido ao estudo de pesticidas (Franke et al., 2013).

Além disso, foi possível calcular a Pegada Hídrica Cinza relativa à produtividade da cultura do tomate na região estudada, através da razão entre PHC e Produtividade da cultura, em que, de acordo com o Instituto Brasileiro de Geografia e Estatística (IBGE), a produtividade do tomate nas cidades de Parelhas e Equador - RN é 45 toneladas por hectares (IBGE, 2017). O estudo de PHC teve como base a área de um hectare, conforme os tratos culturais utilizados nas fazendas locais.

\section{RESULTADOS E DISCUSSÃO}

Rivas Ibáñez et al. (2017) estudando a pegada hídrica cinza em uma indústria de produção de Gazpacho, uma sopa de legumes gelada, destacaram a importância da avaliação de padrões para a aplicação de agrotóxicos em produções agrícolas, associando o número de aplicações à concentração do produto comercial e à taxa de aplicação da substância, visando desta forma, a mitigação dos impactos ao meio ambiente, a água e a saúde humana.

Diante disto, neste estudo foi observado que o fungicida Ridomil Gold foi o agrotóxico com a maior taxa de aplicação (TAS), obtendo um valor de $4,8 \times 10^{-4} \mathrm{t} \mathrm{ha}^{-1}$. Os agrotóxicos que apresentaram menores valores de TAS foram o Karate 50 EC e o Sportak 450 EC, com resultados de $1,3 \times 10^{-1}$ e $1,4 \times 10^{-}$ ${ }^{1} \mathrm{~g} \mathrm{~L}^{-1}$, respectivamente (Tabela 2 ). Com esta análise inicial não foi possível determinar o agroquímico que necessita de maior quantidade de água para diluição da substância ativa no solo (PHC). Entretanto, a TAS é de suma importância para determinação da carga poluente do agrotóxico que será depositada ao decorrer das camadas superficiais e subterrâneas do solo.

Tabela 2. Concentrações das substâncias ativas de agroquímicos aplicados no cultivo de tomate em áreas agrícolas das cidades de Parelhas e Equador, Rio Grande do Norte.

\begin{tabular}{|c|c|c|c|c|c|c|}
\hline $\begin{array}{l}\text { Cultura } \\
\text { (1) }\end{array}$ & $\begin{array}{l}\text { Agroquímicos } \\
\text { (2) }\end{array}$ & $\begin{array}{c}\text { Classe } \\
(3)\end{array}$ & $\begin{array}{l}\text { TACP* (mL/100 L de água) ou } \\
\left(\mathrm{kg} \mathrm{ha}^{-1}\right) \text { ou }\left(\mathrm{L} \mathrm{ha}^{-1}\right)(4)\end{array}$ & $\begin{array}{l}\mathrm{CP} *\left(\mathrm{~g} \mathrm{~L}^{-1}\right) \text { ou } \\
\left(\mathrm{g} \mathrm{kg}^{-1}\right)(5)\end{array}$ & $\begin{array}{l}\text { NA* } \\
(6)\end{array}$ & $\begin{array}{l}\text { TAS }^{*}\left(\mathrm{~g} \mathrm{~L}^{-1}\right) \text { ou }\left(\mathrm{t} \mathrm{ha}^{-}\right. \\
1) 7=(4 \times 5 \times 6)\end{array}$ \\
\hline \multirow{7}{*}{ Tomate } & Evidence & Inseticida & $0,5 \mathrm{~L} \mathrm{ha}^{-1}$ & $480 \mathrm{~g} \mathrm{~L}^{-1}$ & 1 & $2,4 \times 10^{-4} \mathrm{tha}^{-1}$ \\
\hline & Lannate BR & Inseticida & 100 (mL/100 L de água) & $215 \mathrm{~g} \mathrm{~L}^{-1}$ & 3 & $6,5 \times 10^{-1} \mathrm{~g} \mathrm{~L}^{-1}$ \\
\hline & Karate 50 EC & Inseticida & 50 (mL/100 L de água) & $50 \mathrm{~g} \mathrm{~L}^{-1}$ & 5 & $1,3 \times 10^{-1} \mathrm{~g} \mathrm{~L}^{-1}$ \\
\hline & Sportak450 EC & Fungicida & 100 (mL/100 L de água) & $450 \mathrm{~g} \mathrm{~L}^{-1}$ & 3 & $1,4 \times 10^{-1} \mathrm{~g} \mathrm{~L}^{-1}$ \\
\hline & Ridomil Gold & Fungicida & $3,0 \mathrm{~L} \mathrm{ha}^{-1}$ & $400 \mathrm{~g} \mathrm{~L}^{-1}$ & 4 & $4,8 \times 10^{-3} \mathrm{tha}^{-1}$ \\
\hline & Confidor S & Inseticida & $0,5 \mathrm{~kg} \mathrm{ha}^{-1}$ & $500 \mathrm{~g} \mathrm{~kg}^{-1}$ & 2 & $2,5 \times 10^{-4} \mathrm{t} \mathrm{ha}^{-1}$ \\
\hline & Sencor 480 & Herbicida & $1,0 \mathrm{~L} \mathrm{ha}^{-1}$ & $480 \mathrm{~g} \mathrm{~L}^{-1}$ & 1 & $4,8 \times 10^{-4} \mathrm{tha}^{-1}$ \\
\hline
\end{tabular}

*TACP - Taxa de Aplicação Comercial do Produto; CP - Concentração do Produto; NA - Número de Aplicações; TAS - Taxa de Aplicação da Substância.

Estudando os cálculos da pegada hídrica cinza, Franke et al. (2013) define a fração de lixiviação-escoamento como a fração de determinada substância química que é perdida para as águas subterrâneas devido a lixiviação ou para as águas superficiais em função do escoamento. Além disso, os autores relatam que o potencial de contaminação das águas por lixiviação ou escoamento varia em função das características químicas do produto, fatores ambientais, práticas de manejo e da cultura estudada (Tabela 1 ).

Comparando os valores da Tabela 1 com os dados obtidos para cada fator da Tabela 3, verifica-se que os produtos químicos, Karate 50 EC e Ridomil Gold, possuem os maiores valores de coeficiente de partição do carbono orgânico (Koc), o que provavelmente, possui maior interação da substância química ativa destes produtos com a matéria orgânica, ocasionando desta forma, menor taxa de lixiviaçãoescoamento. Segundo Carbo et al. (2008) e Arias Estévez (2008), os agrotóxicos que possuem um Koc baixo, isto é, com baixa tendência a adsorver no solol, pode facilmente alcançar os corpos de água e, portanto, ter maior mobilidade e alta solubilidade. Com isto, eles aumentarão a probabilidade de contaminação das águas subterrâneas. $\mathrm{O}$ alto valor de Koc indica baixa mobilidade, ou seja, maior fixação da substância química com a matéria orgânica, reduzindo a sua lixiviação 
para águas subterrâneas ou escoamento para reservatórios hídricos superficiais (D’AGOSTINHO; FLUES, 2006; FROEHNER; MARTINS, 2008).

Em relação a avaliação das propriedades químicas dos agrotóxicos estudados (Tabela 3), percebe-se que os inseticidas Evidence e Confidor S são os que possuem maior persistência de vida na atmosfera, ou seja, maior tempo de atividade na atmosfera, tanto para lixiviação (PL) quanto para escoamento (PE), com valores de 191 e 30 dias, respectivamente.
Por serem características inerentes à região em estudo, os resultados do potencial de lixiviação-escoamento obtidos para os fatores ambientais (TSL, TSE, MO, $\mathrm{P}$ e IP), observados na Tabela 3, foram iguais para todos os agrotóxicos analisados. Com isso, TSL foi considerado alto $(1,00)$ e TSE muito baixo $(0,00)$, devido à textura do solo das áreas estudadas, isto é, como o solo característico da região é considerado arenoso, portanto, é maior a possibilidade de ocorrer lixiviação (TSL) da substância química ativa e menor a taxa de escoamento (TSE).

Tabela 3. Potenciais de lixiviação-escoamento em relação aos fatores químicos, fatores ambientais e práticas culturais.

\begin{tabular}{|c|c|c|c|c|c|c|c|c|c|}
\hline Agroquímicos & $\mathrm{K}_{\mathrm{oc}}\left(\mathrm{L} \mathrm{kg}^{-1}\right)$ & PL (dias) & PE (dias) & TSL & TSE & $\begin{array}{c}\text { MO } \\
\text { (dag Kg-1) }\end{array}$ & IP & $\begin{array}{c}\mathrm{P} \\
(\mathrm{mm})\end{array}$ & PM \\
\hline \multirow[t]{2}{*}{ Evidence } & $500^{*}$ & 191 & 30 & $\mathrm{~A}$ & A & $\mathrm{B}$ & $\mathrm{B}$ & 551 & $\mathrm{R}$ \\
\hline & $(0,33)^{* *}$ & $(1,00)$ & $(0,33)$ & $(1,00)$ & $(0,00)$ & $(0,33)$ & $(0,00)$ & $(0,00)$ & $(0,67)$ \\
\hline \multirow[t]{2}{*}{ Lannate BR } & 72 & 7,0 & 2,9 & A & A & B & B & 551 & $\mathrm{R}$ \\
\hline & $(0,67)$ & $(0,00)$ & $(0,00)$ & $(1,00)$ & $(0,00)$ & $(0,33)$ & $(0,00)$ & $(0,00)$ & $(0,67)$ \\
\hline \multirow[t]{2}{*}{ Karate 50 EC } & $>1000$ & 175 & 0,24 & A & A & B & B & 551 & $\mathrm{R}$ \\
\hline & $(0,00)$ & $(1,00)$ & $(0,00)$ & $(1,00)$ & $(0,00)$ & $(0,33)$ & $(0,00)$ & $(0,00)$ & $(0,67)$ \\
\hline \multirow[t]{2}{*}{ Sportak 450 EC } & 500 & 120 & 1,0 & A & A & B & B & 551 & $\mathrm{R}$ \\
\hline & $(0,33)$ & $(1,00)$ & $(0,00)$ & $(1,00)$ & $(0,00)$ & $(0,33)$ & $(0,00)$ & $(0,00)$ & $(0,67)$ \\
\hline \multirow[t]{2}{*}{ Ridomil Gold } & $>1000$ & 3,53 & 0,82 & A & A & B & B & 551 & $\mathrm{R}$ \\
\hline & $(0,00)$ & $(0,00)$ & $(0,00)$ & $(1,00)$ & $(0,00)$ & $(0,33)$ & $(0,00)$ & $(0,00)$ & $(0,67)$ \\
\hline \multirow[t]{2}{*}{ Confidor S } & 500 & 191 & 30 & A & A & B & B & 551 & $\mathrm{R}$ \\
\hline & $(0,33)$ & $(1,00)$ & $(0,33)$ & $(1,00)$ & $(0,00)$ & $(0,33)$ & $(0,00)$ & $(0,00)$ & $(0,67)$ \\
\hline \multirow[t]{2}{*}{ Sencor 480} & 41 & 11,5 & 41 & A & A & B & B & 551 & $\mathrm{R}$ \\
\hline & $(1,00)$ & $(0,33)$ & $(0,67)$ & $(1,00)$ & $(0,00)$ & $(0,33)$ & $(0,00)$ & $(0,00)$ & $(0,67)$ \\
\hline
\end{tabular}

$\mathrm{K}_{\mathrm{oc}}$ - Coeficiente de partição de carbono orgânico no complexo solo-água; PL - Persistência relevante de lixiviação (50\% de duração); PE - Persistência relevante de vazão (50\% de duração); TSL - Textura do solo relevante de lixiviação; TSE - Textura do solo relevante de escoamento; IP - Intensidade de precipitação; P - Precipitação; PM - Gestão de práticas relevantes para o fluxo de saída; A - Arenoso; B - Bom e Baixa; R - Ruim. * - Valor encontrado na Bula do Produto; ** - Valor encontrado na Tabela 1.

O teor médio de matéria orgânica $(\mathrm{MO})$ nos solos dos cultivos de tomate nas cidades de Parelhas e Equador - RN (4,2 dag $\mathrm{kg}^{-1}$ ), quando comparado com a classificação da Tabela 1, indicou um valor do potencial de lixiviaçãoescoamento igual a 0,33 (baixo), o que pode favorecer a maior retenção do produto químico à matéria orgânica existente, reduzindo assim, a capacidade de lixiviação ou escoamento destas substâncias para os recursos hídricos próximos às áreas de cultivo do tomate.

Quanto aos fatores climáticos (IP e P) apresentados na Tabela 3, os dois apresentaram valores iguais a 0 , o que pode evidenciar menor taxa de lixiviação-escoamento e menor capacidade de diluição dos agrotóxicos estudados, favorecendo a contaminação dos reservatórios hídricos superficiais e dos lençóis freáticos. Após a obtenção dos valores de potenciais de lixiviação-escoamento de cada fator correspondente às categorias das propriedades químicas da substância ativa, dos fatores ambientais e práticas agrícolas, os mesmos foram inseridos na equação 1, resultando nos valores de $\alpha$ (Tabela 4 ).

Analisando a Tabela 4, observa-se que o herbicida Sencor 480 obteve o maior valor de fração de lixiviaçãoescoamento $(0,057)$, indicando uma menor fixação de sua substância ativa (Metribuzim) com a matéria orgânica. Tal afirmação também pode ser justificada pelo baixo valor do seu Koc (41 L kg-1) (Tabela 3).
Tabela 4. Fração de lixiviação-escoamento de cada agrotóxico.

\begin{tabular}{ccc}
\hline Cultura (1) & Agroquímicos(2) & $\alpha(3)$ \\
\hline & Evidence & 0,050 \\
& Lannate BR & 0,038 \\
Tomate & Karate 50 EC & 0,040 \\
& Sportak 450 EC & 0,047 \\
& Ridomil Gold & 0,025 \\
& Confidor S & 0,050 \\
& Sencor 480 & 0,057 \\
\hline
\end{tabular}

$\alpha$ - Fração de lixiviação-escoamento.

O cálculo da Pegada Hídrica Cinza expressa a quantidade de água doce necessária para diluir a substância ativa do produto químico no solo, a partir da carga poluente aplicada anualmente (L) e da concentração máxima permitida de aplicação pelas legislações nacionais e internacionais (Cmax). Hoekstra et al. (2012) sugerem que o valor de Cmax seja obtido através das legislações nacionais, entretanto, se a legislação em vigor não conter dados de Cmax relacionados à determinada substância, pode-se utilizar legislações internacionais para este fim.

Diante do exposto, das características inerentes aos agrotóxicos estudados, das propriedades ambientais e agrícolas das áreas em questão, incluindo a produtividade do tomate de $45 \mathrm{t} \mathrm{ha}^{-1}$ (IBGE, 2017), verifica-se que o agrotóxico que necessita da maior quantidade de água doce para sua diluição é o Ridomil Gold, apresentando valor da PHC de $14666,67 \mathrm{~m}^{3} \mathrm{t}^{-1}$, seguido do Confidor $S\left(1266,67 \mathrm{~m}^{3} \mathrm{t}^{-1}\right)$ e Evidence $\left(1155,55 \mathrm{~m}^{3} \mathrm{t}^{-1}\right.$ ), respectivamente (Tabela 5). 
Pegada hídrica cinza no cultivo de tomate no semiárido brasileiro

Tabela 5. Pegada Hídrica Cinza em relação à produtividade do tomate nas cidades de Equador e Parelhas, Rio Grande do Norte.

\begin{tabular}{cccccccc}
\hline $\begin{array}{c}\text { Cultura } \\
(1)\end{array}$ & $\begin{array}{c}\text { Agroquímicos } \\
(2)\end{array}$ & $\begin{array}{c}\alpha \\
(3)\end{array}$ & $\begin{array}{c}\mathrm{T}_{\text {talp }}(\mathrm{t}) \\
(4)\end{array}$ & $\begin{array}{c}\mathrm{L}(\mathrm{t}) \\
5=(3) \times(4)\end{array}$ & $\begin{array}{c}\text { Cmax }\left(\mathrm{t} \mathrm{m}^{-3}\right) \\
(6)\end{array}$ & $\begin{array}{c}\mathrm{PHC}^{*}\left(\mathrm{~m}^{3}\right) \\
7=(5) /(6)\end{array}$ & $\mathrm{GWF}^{2}\left(\mathrm{~m}^{3} \mathrm{t}^{-1}\right)$ \\
\hline \multirow{5}{*}{ Tomate } & Evidence & 0,050 & $2,4 \times 10^{-4}$ & $1,2 \times 10^{-5}$ & $2,3 \times 10^{-10}$ & $5,2 \times 10^{4}$ & 1155,55 \\
& Lannate BR & 0,038 & $6,5 \times 10^{-7}$ & $2,5 \times 10^{-8}$ & $1,0 \times 10^{-10}$ & 250 & 5,56 \\
& Karate 50 EC & 0,040 & $1,3 \times 10^{-7}$ & $5,2 \times 10^{-9}$ & $1,0 \times 10^{-10}$ & 52 & 1,16 \\
& Sportak 450 EC & 0,047 & $1,4 \times 10^{-7}$ & $6,6 \times 10^{-9}$ & $1,0 \times 10^{-10}$ & 66 & 1,47 \\
& Ridomil Gold & 0,025 & $4,8 \times 10^{-3}$ & $1,2 \times 10^{-4}$ & $1,8 \times 10^{-10}$ & $6,6 \times 10^{5}$ & 14666,67 \\
& Confidor S & 0,050 & $2,5 \times 10^{-4}$ & $1,3 \times 10^{-5}$ & $2,3 \times 10^{-10}$ & $5,7 \times 10^{4}$ & 1266,67 \\
& Sencor 480 & 0,057 & $4,8 \times 10^{-4}$ & $2,5 \times 10^{-5}$ & $5 \times 10^{-10}$ & 5000 & 111,11 \\
\hline
\end{tabular}

$\alpha$ - Fração de lixiviação-escoamento; Ttalp - Taxa de aplicação da substância; L - Carga poluente do produto; Cmax - Concentração máxima permitida para aplicação; PHC - Pegada hídrica cinza.

Entre os agrotóxicos avaliados, três deles foram considerados de baixo impacto ao meio ambiente, devido à baixa necessidade de água para diluição de seus contaminantes, com valores da PHC de 1,16 $\mathrm{m}^{3} \mathrm{t}^{-1}$ (Karate 50 EC), $1,47 \mathrm{~m}^{3} \mathrm{t}^{-1}$ (Sportak $450 \mathrm{EC}$ ) e $5,56 \mathrm{~m}^{3} \mathrm{t}^{-1}$ (Lannate BR). Com estes resultados, até a própria precipitação proveniente das regiões de Parelhas e Equador - RN que é de $551 \mathrm{~mm}$, pode ajudar na diluição, evitando desta forma, a utilização de águas oriundas dos reservatórios hídricos. Matos et al. (2017), quantificaram a PHC da produção de cebola para a região do Vale do São Francisco, nos estados de Pernambuco, Alagoas e Bahia, e obtiveram valores da PHC para os agrotóxicos Karate 50 EC $\left(1140 \mathrm{~m}^{3} \mathrm{t}^{-1}\right)$ e Sportak 450 EC $\left(60750 \mathrm{~m}^{3} \mathrm{t}^{-1}\right)$, maiores ao deste estudo. Essa diferença nos valores da PHC, provavelmente, ocorreu devido as características ambientais entre as regiões e também pelas culturas estudadas.culturais. Segundo Pina (2010), a PHC depende do tipo de poluente e também das concentrações máximas permitidas para o local de estudo.

\section{CONCLUSÕES}

Os agrotóxicos Evidence (Imidaclopido), Ridomil Gold (Clorotalonil) e Confidor S (Imidaclopido) apresentam maior pegada hídrica cinza para o cultivo de tomate para as regiões de Equador e Parelhas - RN, proporcionando maior exigência de água doce para diluição dos poluentes.

O inseticida Ridomil Gold (Clorotalonil) é bastante ofensivo para a produção de tomate, devendo ser evitada sua aplicação.

\section{REFERÊNCIAS}

ARIAS-ESTEVEZ, M.; LOPEZ-PERIAGO, E.; MARTÍNEZ-CARBALLO, E.; SIMAL-GANDARA, J.; MEJUTO, J.; GARCIA-RI, O. L. The mobility and degradation of pesticides in soils and the pollution of groundwater resources. Agriculture, Ecosystems \& Environment, v.123, n.4, p.247-260, 2008. https://doi.org/10.1016/j.agee.2007.07.011.

CARBO, L.; SOUZA, V.; DORES, E. F. G. C.; RIBEIRO, M. L. Determination of pesticides multiresidues in shallow groundwater in a cotton-growing region of Mato Grosso, Brazil. Journal of the Brazilian Chemical Society, v.19, n.6, p.1111-1117, 2008. http://dx.doi.org/10.1590/S010350532008000600009.
CMME, Canadian Council of Ministers of the Environment. Chemicals. 2018. Disponível em: <http://stts.ccme.ca/en/index.html>. Acesso em: 28 jun. 2018.

COSTA, P. S.; FERRAZ, R. L. S.; DANTAS NETO, J.; ANJOS, F. A.; CAVALCANTE JÚNIOR, C. A.; BARRETO, N. P.; MEDEIROS, A. S.; BARBOSA, M. A.; MAGALHÃES, I. D.; SANTOS, S. L. Virtual water consumption: a case study in a higher education institution in northeast Brazil. Journal of Scientific Research \& Reports, v.18, n.1, p.1-12, 2018. http://dx.doi.org/10.9734/JSRR/2018/39250.

BRASIL. Ministério do Meio Ambiente. CONAMA 357/2005 - Dispõe sobre a classificação dos corpos de água e diretrizes ambientais para o seu enquadramento, bem como estabelece as condições e padrões de lançamento de efluentes, e dá outras providências. Diário Oficial da União 18/03/2005. 2005. Disponível em: <http://pnqa.ana.gov.br/Publicacao/RESOLUCAO_CONAM A_n_357.pdf $>$. Acesso em: 11 de nov. de 2018.

D’AGOSTINHO, A.; FLUES, M. Determinação do coeficiente de distribuição $(\mathrm{Kd})$ de benzo(a)pireno em solo por isotermas de sorção. Química Nova, v.29, n.4, p. 657-661, 2006. http://dx.doi.org/10.1590/S0100-40422006000400006.

EUR, Europe Union Law. Directiva 2008/105/ce do parlamento europeu e do conselho. 2008. Disponível em: $<$ https://eur-lex.europa.eu/legal-

content/PT/TXT/?uri=CELEX:32008L0105>. Acesso em: 25 jun. 2018.

FRANKE, N. A.; BOYACIOGLU, H.; HOEKSTRA, A. Y. Grey Water Footprint Assessment: Tier 1 - Supporting Guidelines, Water Footprint Network, Enschede, The Netherlands. UNESCO-IHE, Institute for WaterEducation .Delft. 2013.

FROEHNER, S.; MARTINS, R. F. Avaliação do destino e bioacumulação de benzo(a)pireno através de simulação computacional. Química Nova, v. 31, n. 5, p. 1089-1093, 2008. http://dx.doi.org/10.1590/S0100-40422008000500028.

HOEKSTRA, A. Y.; MEKONNEN, M. M.; CHAPAGAIN, A. K.; MATHEWS, R. E.; RICHTER, B. D. Global monthly water scarcity: blue water footprints versus blue water 
availability. PlosOne, v. 7, n. 2, p. 1-32, 2012. https://doi.org/10.1371/journal.pone.0032688.

IBGE, Instituto Brasileiro de Geografia e Estatística. Censo Agropecuário. 2017. Disponível em: <https://cidades.ibge.gov.br/brasil/rn/>. Acesso em: $13 \mathrm{de}$ nov. de 2018.

LIMA, W. T.; OLIVEIRA, A. M. L.; SILVA, I. O.; TANANTA, C. T.; COSTA, H. Uma geopolítica para as águas continentais na Amazônia Ocidental. Revista de Geopolítica, v. 9, n. 1, p. 11-21, 2018.

LOVARELLI, D.; BACENETTI, J.; FIALA, M. Water Footprint of crop productions: A review. Science of the Total Environment, v. 548-549, n. 1, p. 236-251, 2016. https://doi.org/10.1016/j.scitotenv.2016.01.022.

MATOS, R. M.; BORGES, V. E.; LIMA, A. S.; SILVA, P. F.; NETO, J. D.; LIMA, V. L. A. Sustainability of the grey water footprint (GWF) for cultivation of onion in the Brazilian semi-arid regions. Australian Journal of Crop Science, v. 11, n. 6, p. 749-756, 2017. https://doi.org/10.21475/ajcs.17.11.06.p569

PAGE, G.; RIDOUTT, B.; BELLOTTI, B. Carbon and water footprint tradeoffs in fresh tomato production. Journal of Cleaner Production, v, 32, n. 1, p. 219-226, 2012. https://doi.org/10.1016/j.jclepro.2012.03.036.

PALHARES, J. C. P. Pegada hídrica de suínos e o impacto de estratégias nutricionais. Revista Brasileira de Engenharia Agrícola e Ambiental, v. 18, n. 5, p. 533-538, 2014. http://dx.doi.org/10.1590/S1415-43662014000500010.

PINA, L. A. B. Pegada Hídrica associada à produção do vinho verde branco. 2010. 92f. Dissertação (Mestrado) Departamento de Ambiente e Ordenamento. Universidade de Aveiro, Portugal. 2010.

RAMÍREZ, T.; MEAS, Y.; DANNEHL, D.; SCHUCH, I.; MIRANDA, L.; ROCKSCH, T.; SCHMIDT, U. Water and carbon footprint improvement for dried tomato value chain. Journal of Cleaner Production, v. 104, n. 1, p. 98-108, 2015. https://doi.org/10.1016/j.jclepro.2015.05.007.

RIVAS IBÁÑEZA, G.; MOLINA RUÍZ, B. J. M.; ROMÁN SÁNCHEZ, M. I.; CASAS LÓPEZA, J. L. A corporate water footprint case study: The production of Gazpacho, a chilled vegetable soup. Water Resource and Industry, v.17, n. 1, p. 34-42, 2017. https://doi.org/10.1016/j.wri.2017.04.001.

SANTIAGO, A. D.; CHICO, D.; ANDRADE JUNIOR, A. S.; GARRIDO, A.; CARNAÚBA, P. J. P. Pegada hídrica da cana-de-açúcar e etanol produzidos no estado de Alagoas, Brasil. Agrometeoros, v. 25, n. 1, p. 209-216, 2017.

SILVA, T.; MOREIRA, A. Agrotóxicos: Um estudo acerca dos conhecimentos de agricultores sobre o uso dos agrotóxicos utilizados nos municípios de Parelhas-RN e Equador-RN para o cultivo do tomate. In: $52^{\circ}$ Congresso Brasileiro de Química. Recife-PE. 2012. Disponível em: <http://www.abq.org.br/cbq/2012/trabalhos/5/80110817.html>. Acesso em: 20 jun. 2018.

US-EPA, United States Environmental Protection Agency. National Recommended Water Quality Criteria - Aquatic Life Criteria Table. 2018. Disponível em: <https://www.epa.gov/wqc/national-recommended-waterquality-criteria-aquatic-life-criteria-table\#main-content>. Acesso em: 28 jun. 2018. 